\title{
Autoritarismo judiciário e precariedade de defesa das camadas populares no Brasil: Uma herança perversa
}

\author{
ROCHA, Paula ${ }^{1}$ \\ JORDÃO, Maria Perpétua Socorro Dantas²
}

\section{Resumo}

O presente ensaio propõe uma reflexão sobre a dificuldade de acesso aos mecanismos de justiça e precariedade de defesa das camadas populares no Brasil frente a uma postura autoritária por parte das esferas de decisão personificadas pelo Poder Judiciário. Temos uma constituição democrática que garante direitos difusos, e coletivos, mas que na prática, quando falamos de direitos inerentes aos mecanismos processuais do uso do contraditório e da ampla defesa por exemplo, vimos que na prática são direitos que não se concretizam plenamente para ricos e pobres. A proposta do presente texto é mostrar que quanto maior é o grau de exclusão de um indivíduo, maior é seu distanciamento das garantias legais e constitucionais quando nos referimos aos mecanismos de defesa dentro do ordenamento jurídico formal, já que em regra é atendido por uma defensoria pública sobrecarregada, com poucos recursos e muitas vezes precárias condições para realizar uma defesa plena e irrestrita, como diz a norma. Ainda abordamos a herança autoritária dos períodos de ditadura e seus reflexos em práticas processuais retificando um procedimento violador de direitos e uma lei altamente seletiva e segregatória. Por fim nosso trabalho é fruto de pesquisa qualitativa e bibliográfica sendo concluído com um olhar voltado para a necessidade urgente de mudanças na formação dos profissionais do direito, humanizando-os. Quando assim acontecer teremos um sistema de justiça criminal que busque de fato justiça com equidade garantindo a todos os cidadãos brasileiros igualdade de armas na busca por uma decisão justa.

Cidadania. Autoritarismo. Sistema de justiça. Ampla defesa.

\section{Resumen}

El presente ensayo propone una reflexión acerca de la dificultad de acceso a los mecanismos de la justicia y la precariedad de defensa de las camadas populares en Brasil frente a una postura autoritaria por algunas de las esferas de decisión, personificadas por el Poder Judiciario.Tenemos una constitución democrática que garante derechos difusos, y colectivos, pero en la práctica, cuando hablamos de derechos inherentes a los mecanismos procesuales del uso del contradictorio y de la amplia defensa, por ejemplo, vimos que en la práctica son derechos que no se concretan ampliamente para ricos y pobres. La propuesta del presente texto es mostrar que cuanto mayor es el grado de exclusión de un individuo, mayor es su distanciamiento de las garantías legales y constitucionales, cuando nos referimos a los mecanismos de defensa del ordenamiento jurídico formal, ya que en regla es atendido por una defensoría pública sobrecargada, con pocos recursos y muchas veces precarias condiciones para realizar una defensa plena e irrestricta, como lo he dicho en la norma. Aún abordamos la herencia autoritaria de los períodos de dictadura y sus reflejos en las prácticas procesuales, rectificando un procedimiento violador de

\footnotetext{
${ }^{1}$ Doutora em Desenvolvimento Urbano (UFPE), Doutoranda em Direito (UNICAP), professora de Direito Penal da ASCES/UNITA, integrante do Programa Adoção Jurídica de Cidadãos Presos desde 2001. ${ }^{2}$ Mestre em Ciência Política, Professora de Direito Processual Penal da ASCES/UNITA - Caruaru, Coordenadora do Escritório de Práticas Jurídicas da ASCES/UNITA. Secretaria de Políticas para as Mulheres do Município de Caruaru. Coordenadora do Programa de Adoção Jurídica de Cidadãos Presos desde 2001.
} 
derechos y una ley altamente selectiva y segregadora. Por fín, nuestro trabajo es fruto de pesquisa cualitativa y bibliográfica siendo concluido con un mirar vuelto para la necesidad urgente de mudanzas na formación de los profesionales de derecho, dejándolos más humanos. Cuando así acontecer tendremos un sistema de justicia criminal que busque de facto justicia con equidad garantindo a todos los ciudadanos brasileños igualdad de armas en la búsqueda por una decisión justa.

\section{Cidadania. Autoritarismo. Sistema de justicia. Amplia defensa.}

\section{Introdução}

Neste artigo, realizamos uma análise política das consequências da precariedade da defesa das camadas populares, e como o autoritarismo permanente no poder judiciário, contribui para a manutenção das violações de direitos humanos desse segmento marcado pela exclusão social. Para tanto, recorremos a um referencial teórico interdisciplinar, por compreender, que discutir cidadania, exclusão, e a constituição de uma sociedade democrática, passa necessariamente por um novo olhar sobre a instituição da cidadania no Brasil.

Em um país, organizado sob uma ordem patrimonialista, o privilégio das classes mais abastadas no interior do Estado sempre permitiu a licenciosidade das elites, sob o direito das massas (HOLANDA, 1988, p. 106). A cidadania nesta sociedade de bacharéis fazia 0 acesso a cidadania se concretizar pelo privilégio e pela propriedade (HOLANDA, 1988, p. 109). Criamos um país, marcado pelo autoritarismo das elites, marcado pela licenciosidade da vida pública e privada, onde "tudo é Estado e nada é sociedade civil" (FAORO, 1975, p. 47). A ausência de canais de acesso aos direitos das camadas populares acabou se constituindo em um comportamento "natural", internalizado pelo próprio oprimido, numa absorção do modelo dominante, de inferiorização e sujeição ao Estado ou seus representantes (BARROS, 2002, p. 72).

Inúmeros preceitos legais norteiam o Direito. Recortemos o significado da amplitude de defesa que a todos é garantido formalmente, o princípio do contraditório, que na prática, significa que é ofertada pelo Estado de direito às partes em litígio, a possibilidade de expor as suas teses, de exercerem seu direito de defesa como garantia do acesso a cidadania, e que acima de tudo, estas partes em litígio, serão tratadas com isonomia, pela importância do princípio de igualdade na afirmação e proteção dos direitos humanos em um estado de direitos: Estejamos nos referindo a pessoa humana da vítima ou a pessoa humana do réu.

No entanto, a previsão desses direitos pelo nosso ordenamento jurídico, não significa a porta de acesso aos mesmos. É necessário observar que a realidade cotidiana de acesso ao judiciário pelas partes é diferenciada. No caso das camadas populares que enfrentam imensas dificuldades quando buscam o acesso à Justiça. "aos litigantes em processo judicial ou administrativo, e aos acusados em geral, são assegurados o contraditório a ampla defesa, com os 
meios e recursos a ela inerentes" (CF, 1988, p. 65). Mas como exercer estes direitos se as ferramentas de acesso não estão disponíveis a todos da mesma forma? Sadek, (1992, p. 34) descreve que os mecanismos de acesso à Justiça não são uniformes, dependendo do agente que requer o direito, e as condições que o fazem alheio ou não ao Sistema de Justiça. Quanto maior o seu grau de escolaridade, de condições econômicas, posição social, terá melhores condições de acompanhamento dos mecanismos judiciais. Sendo assim, as camadas populares estão submetidas aos piores processos de exclusão: analfabetismo, baixa escolaridade, violência, desemprego, informação deficitária, pouca influência política e precariedade de moradias, entre outras. Soma-se a essa situação a precariedade das estratégias de acesso ao judiciário, em geral através da defensoria pública que possui geralmente poucos defensores para atuar nos litígios que envolvem as camadas populares e as pessoas pobres na forma da lei.

O Estado-juiz julgará o mérito da causa com imparcialidade, não se deixando influenciar por fatos ou circunstâncias alheias ao processo. "o que não está nos autos, não está no mundo" (CAPEZ, 2002, p. 83). Até que ponto nossas concepções de mundo, de classes, não acompanham nossas ações no espaço público ou privado? Se o direito é uma ciência, não podemos esquecer que "todo pensamento é tributário de seu tempo" (SODRÉ, 1984, p. 75). Dessa forma, também o pensamento jurídico, está impregnado pela matriz ideológica da qual se origina.

\section{Art. 157 do Código de Processo Penal:}

O juiz formará sua convicção pela livre apreciação da prova. [...] O Juiz está adstrito às provas dos autos, não podendo fundamentar qualquer decisão em elementos a eles estranhos: o que não está nos autos não está no mundo (quod non est in actis non est in mundo. (MIRABETE, 2000, p. 256)

Quando começamos a lidar com a realidade no exercício do Direito $^{3}$ começamos a compreender a dicotomia: Teoria - prática. $\mathrm{O}$ quanto o direito previsto não consegue se materializar na realidade prática. A realidade do mundo jurídico 4 causa ao cidadão comum o desânimo para seguir em frente na defesa dos seus direitos. Quando ao contrário, a negação deste direito deveria surtir neste excluído a vontade de questionar o modelo excludente, aproximando-o de instâncias de controle social: associações de moradores, núcleos comunitários de cidadania, instrumentos de pressão que contribuem para modificar o panorama tão desolador que constitui o acesso à Justiça e aos

\footnotetext{
${ }^{3}$ A partir do Estágio curricular, mas, recortamos especificamente as experiências obtidas no Projeto de Extensão: Adoção Jurídica de Cidadão Presos da Faculdade de Direito de Caruaru, tendo como fonte empírica de dados, as entrevistas realizadas com os alunos, professores e adotivos do projeto.

${ }^{4}$ A realidade da qual falamos é a morosidade da justiça, a dificuldade de constituir uma defesa comprometida com a sua causa, e a situação de desigualdade econômica entre os réus pobres e os cidadãos que conseguem o acesso à justiça: Por condição econômica, social ou intelectual favorável.
} 
demais direitos no Brasil, convidando outros setores da sociedade civil a participar de sua luta (PINHEIRO, MENDEZ E O'DONNELL, 2000, p, 11).

\section{Um legado cultural}

A transição da ditadura militar para um regime civil no Brasil recente ${ }^{5}$ criou a expectativa que a conquista da democracia seria a chave para a passagem do autoritarismo para um Estado de Direito (BOBBIO, 1956, p. 52), de igualdade de direitos e de respeitos a princípios fundamentais.

Esse contexto social e político agravou-se ainda, ao longo dos
anos 80 , uma vez que a democratização brasileira não foi
acompanhada da redução das desigualdades sociais. Ao
contrário, ampliou-se o fosso entre as legítimas expectativas de
mobilidade social e as aspirações coletivas, estimuladas pelo
êxito pessoal e pela desenfreada expansão do consumo, ideais
socialmente perseguidos como os únicos meios possíveis de
reconhecimento de dignidade, de acesso aos direitos e,
portanto, de alcance da cidadania. (ADORNO, CARDIA, 1999:
$74-75$ )

É necessário discutir que com a promulgação da Constituição Federal de 1988 conseguimos derrubar a ditadura política e instaurar um Estado de Direito. Porém, continuamos convivendo com o cotidiano de um país profundamente desigual e injusto, herdeiro de comportamentos racistas e discriminatórios. Dentro desse contexto violamos de outras formas os direitos humanos, principalmente quando observamos a exclusão das camadas populares no Brasil e mais ainda, quando falamos de acesso destes pobres ao Sistema de Justiça.

Esses campos negativos e positivos estão marcados pelos elementos dos legados históricos e dos períodos autoritários recentes, da sobrevivência de um autoritarismo socialmente implantado que o fim do regime de exceção não elimina, dos efeitos de períodos prolongados de concentração de renda e de desigualdade social e racial, dos preconceitos, dos micro despotismos. (PINHEIRO, MENDEZ e O'DONNELL, 2000, p. 11).

O autor faz referências a dois campos políticos distintos, onde o negativo é a sociedade dos não-cidadãos, dos miseráveis e o campo positivo da sociedade formada pelas elites. Todo esse processo de consolidação democrática pelo qual o Brasil tem passado padece de uma crise generalizada onde podemos claramente identificar influências do "velho" autoritarismo presente no cotidiano de algumas instituições nacionais, herdeiras do coronelismo, nepotismo e discriminações sociais e de classes (BARROS, 2002:

5 Iniciado em 1985. 
95). Dentre tantas, pontuaríamos especialmente as polícias: Civil e Militar e o Poder Judiciário, este último, foco de nosso estudo.

$\mathrm{Na}$ afirmação de Sérgio Paulo Pinheiro "sob a democracia prevalece um sistema autoritário, incrustado em especial nos aparelhos do Estado de controle da violência e do crime" (PINHEIRO, MENDEZ E O'DONNELL, 2000, p. 11). Percebemos o foco da problemática que não é recém-nascida no campo da Ciência Política. Entretanto, pouco levada a um debate mais amplo no campo do Direito, razão pela qual ousamos tocar nessa ferida, que expõe o direito em uma distância imensa das camadas populares, distância que amplia a exclusão das camadas populares e impede que o direito cumpra a sua função social quando deveria estar atuando com isonomia em defesa dos direitos dos mais pobres também.

A tardia modernidade penal entre a hipertrofia e minimização do sistema penal, proclama, com grande oportunidade a enorme distância entre o ensinamento jurídico, fundamentado em princípios clássicos e a vida real, onde imperam outros princípios e critérios. (SCHERRER, 2003, p.239).

Tendo em vista a estreita relação entre Direito e poder político, torna-se essencial que a ordem legal, que organiza e justifica o exercício do poder de uma sociedade, seja justa e moralmente compartilhada pelos membros da comunidade. Quando isso não acontece, temos a sensação de que a Lei não é feita para todos, pois dependendo das circunstâncias, apenas alguns são beneficiados pela legislação, o que nos traz uma certeza de que temos muito desafios que ainda impedem a consolidação de uma democracia nos termos da declaração constitucional de serem "todos os homens iguais perante a lei". Todos são iguais perante a lei, sem distinção de qualquer natureza, garantindose aos brasileiros e aos estrangeiros residentes no país a inviolabilidade do direito à vida, à liberdade, à igualdade, à segurança e à propriedade"(CF de 1988-2000, p. 12).

Situação que chega a nos lembrar Thomas Hobbes (HOBBES apud WEFFORT, 2002, p. 54), quando em sua teoria política narrava a celebração de um contrato social entre o soberano absolutista e os cidadãos. Vale lembrar que naquela circunstância, participavam do contrato social apenas os "cidadãos", e naquele período histórico nem todos eram considerados cidadãos para estarem protegidos pelo contrato social. Sabe-se que a cidadania estava diretamente ligada à propriedade privada, e posteriormente a burguesia.

Para a teoria liberal dos séculos XVIII e XIX, a lei penal enquanto manifestação da vontade geral, não discrimina nenhum tipo de grupo social e não favorece nenhum interesse particular" (...). Nele, cada indivíduo é titular de seus direitos se for um sujeito 'racional' digno de gozar desses direitos. A lei penal é violada somente por um restrito grupo de pessoas que, ao contrário da maioria dos cidadãos, são incapazes de seguir 
a própria vontade racional, e portanto, de julgar o que é bem e o que é mal, o que é justo ou que é injusto. Quem comete um crime, sobretudo se reincidente, demonstra não ser um ser racional e, portanto, de não merecer a titularidade dos direitos: é uma pessoa que não desenvolveu um autocontrole suficiente, e por esse motivo, não é digna de gozar dos benefícios do contrato social. (SANTORO, 2002, p. 60)

Voltando ao nosso tema, procuramos fazer com a passagem acima, uma analogia com o que acontece com os brasileiros que estão a mercê de nossa legislação criminal onde os laureados são os verdadeiros cidadãos e os desgraçados aqueles que estão longe do exercício da cidadania e de serem tratados como cidadãos sujeitos de direito (SADEK, 2001, p. 72).

Com esse tratamento diferenciado que é dado aos pobres e as elites em nosso país, quem trabalha com o direito penal e ao mesmo tempo começa a desvendar as veredas da Ciência Política tem a sensação de que temos em vigor duas legislações no Brasil, divididas em leis oficiais, e extra - oficiais, onde cada uma encontra-se destinada a certo segmento da população ${ }^{6}$.

A realidade mostra que os órgãos da Justiça assumem uma distância considerável do cotidiano do homem comum. Sob a influência de conceitos ideológicos que veem na aplicação do direito um mecanismo 'neutro', imune a impressões subjetivas dos seus 'operadores', a máquina judiciária passa a funcionar em torno de um mundo próprio, em que despontam o rigor burocrático e o culto exagerado à lei. Essa concepção estabelece uma profunda desigualdade na distribuição da justiça, elaborando, a um só tempo, um direito para os oprimidos - rígido, implacável e eficiente como instrumento de repressão - e um direito das elites, repleto de artifícios e sofisticados exercícios de interpretação que servem para manter uma 'paz social' cujos benefícios são repartidos entre poucos. (JUSTIÇA COM CONTROLE POPULAR, 2003, p.1).

Dizer que vigoram duas legislações que tratam da mesma matéria no nosso território nacional, pode parecer estranho e contraditório. Mas nosso problema não é uma análise apenas ponto de vista jurídico, pois vai além de preceitos doutrinários, dogmáticos e tradicionais. É principalmente um problema político que tem relação direta com o processo de exclusão social e produção da desigualdade e da indiferença no Brasil.

Podemos observar que temos duas sociedades: uma composta por integrantes das elites, também chamadas de sociedade civil e outra composta por milhões de pobres e miseráveis, que vamos chamar, como no texto de Paulo Sérgio Pinheiro sociedade incivil.

6 ADORNO, Sérgio. Os Aprendizes do Poder. Editora Paz e Terra: RJ, 1997. P.38 
O que chama a atenção na América Latina, e particularmente no Brasil, por causa de sua dimensão, é que essas formas de incivilidade se abatem de preferência sobre as maiorias que constituem as populações pobres e miseráveis, precisamente aqueles setores que são os alvos do arbítrio, da criminalização e da discriminação. (grifos nossos). (PINHEIRO, MENDEZ e O'DONNELL, 2000, p. 12)

É justamente a essa sociedade "incivil" que posturas autoritárias demonstram a face mais sombria de nossa democracia. A fragilidade, a falta de representação nos três poderes, a ausência de recursos financeiros, o acesso à educação e a ausência de mecanismos de denúncias das violações sofridas, faz dessa sociedade desprovida de direitos mais suscetíveis às mais variadas formas violações (ANISTIA INTERNACIONAL, 2001, p.84).

\section{0 acesso à justiça e a amplitude de defesa}

Fazendo um paralelo entre o período da ditadura militar e a atualidade, no que concerne aos meios de repressão do aparelho do Estado, Flávia Piovesan em sua obra, observa:

Se no período de autoritarismo do regime militar aqueles que eram acusados de oferecer resistência ao regime eram torturados ou arbitrariamente detidos por razões de natureza política, no processo de democratização o padrão de conflituosidade se orienta por outro critério. Não se trata mais de critério político, mas do critério econômico, ao qual se conjuga um componente sócio-político. Neste sentido, as vítimas não são mais dos setores da classe média, politicamente engajados, mas pessoas pobres, por vezes marginalizadas socialmente, sem que apresentem qualquer liderança destacada. (Piovesan, 1997, p. 297).

No Brasil a Constituição Federal assegura o sistema acusatório no processo penal, sistema este que tem por característica alguns princípios, como é o caso do "princípio do contraditório e da ampla defesa, com os meios e recursos a ela inerentes" (art. $5^{\circ}$ LV da Carta Magna) (MIRABETE, 2000, p. 41).

Questionamos justamente a eficácia dessas garantias fundamentais diante da dificuldade de acesso ao Sistema de Justiça pelas classes populares, por desconhecerem esses direitos, ou mesmo os reconhecendo, não disporem de meios para efetivá-los. Essa situação gera uma afronta à garantia dos direitos humanos do acusado já que lhe é negado a igualdade processual entre as partes.

Estudos revelam que a distância dos cidadãos em relação à administração da justiça é tanto maior quanto mais baixo é o estrato social a que pertencem e que esta distância tem como 
causas próximas não apenas factores econômicos, mas também factores sociais e culturais, ainda que uns e outros possam estar mais remotamente relacionados com as desigualdades econômicas (...). Os cidadãos de menor recursos tendem a reconhecer pior os seus direitos e, portanto, a ter mais dificuldades em reconhecer um problema que os afecta como sendo um problema jurídico. (SANTOS, 2001, p. 170).

Os réus das camadas populares, defendidos por patrocinadores públicos, não conseguem ter a compreensão que mesmo havendo a "presença" do defensor nos autos as suas garantias constitucionais podem ser violadas no processo. Não é o fato dos defensores serem indiferentes a estas violações, muitas vezes nem as percebem. É o somatório de vários problemas, onde o limitado número de advogados públicos para uma demanda processual imensa é apenas umas das faces mais visíveis destas violações quanto ao acesso pleno ao Sistema de Justiça. Essa situação compromete o bom andamento nos julgamentos, o que viola vários direitos, gerando entre classes sociais distintas, uma distribuição discriminatória do acesso à Justiça.

$\mathrm{Na}$ justiça penal há, por assim dizer, uma procura forçada da justiça, nomeadamente por parte do réu; no entanto, a nível global, pode igualmente falar-se de procura social da Justiça Penal (...). Não se trata de um problema novo. No princípio do século, tanto na Áustria como na Alemanha foram frequentes as denúncias da discrepância entre a procura e a oferta da justiça e foram várias as tentativas para minimizar o problema, quer por parte do Estado, quer por parte dos interessados das classes sociais mais débeis (por exemplo, os centros de consulta jurídica organizados pelos sindicatos alemães) (...). O conjunto desses estudos revelou que a discriminação social no acesso à justiça é um fenômeno muito mais complexo do que à primeira vista pode parecer, já que, para além das condicionantes econômicas, sempre mais óbvias, envolve condicionantes sociais e culturais, resultantes de processos de socialização e de interiorização de valores dominantes muito difíceis de transformar. (SANTOS, 2001, p. 170).

A não-amplitude de defesa que é usurpada dos réus pobres, em função da discriminação social no acesso à justiça em nosso país, é uma realidade perversa no mundo jurídico, onde não é raro na esfera penal, presos que foram julgados praticamente sem exercer sua defesa. ${ }^{7}$

O relatório da Anistia Internacional de 2001 aponta que os direitos básicos como o acesso a familiares; advogado e médico costumam ser ignorados. Segundo o relatório do relator especial da ONU sobre tortura, vimos a seguinte situação:

\footnotetext{
${ }^{7}$ A qualidade da assistência jurídica, o gozo das garantias processuais e constitucionais, são alguns dos elementos que caracterizam uma defesa.
} 
Durante suas visitas a carceragens policiais, constatou-se que a maioria dos suspeitos acreditavam que as respectivas famílias não haviam sido informadas sobre sua prisão e paradeiro, bem como, as pessoas detidas não tinham assistência de advogado. Foi informado pelo contrário, de que, nos poucos casos em que o detido teve advogado particular, este fora impedido de ver o cliente antes da conclusão da instrução preliminar (...). Detentos oriundos de setores carentes da sociedade têm pouco ou nenhum acesso à representação jurídica, embora a Constituição requer que o Estado a proporcione. Muitos poucos Estados instituíram Defensoria Pública, conforme determina a Constituição, e nos Estados que proporcionam essas defensorias, a mesma sofre insuficiência de pessoal e verba. (ANISTIA INTERNACIONAL, 2001, p. 93).

São por essas razões que temos uma concepção política do direito à "amplitude de defesa", e não apenas uma concepção dogmática de sua efetivação, principalmente, quando se trata de réus pobres submetidos ao nosso sistema processual penal. A democratização do Judiciário depende de uma política de distribuição igualitária do acesso à justiça onde todos os cidadãos possam de fato usufruir dos princípios constitucionais vigentes.

A democratização do Judiciário pode ser demarcada na área do acesso à justiça e materializar, pelo alargamento da possibilidade maior de encaminhamento de demandas sociais, acarretando em consequência, uma probabilidade de mudança de seu perfil tradicional de compromissos políticos. (VIEIRA, 1995, p.71).

\section{Uma visão jurídica em crise}

A visão excessivamente dogmática dos profissionais do direito: advogados, juízes promotores, e as demais figuras do cenário jurídico, agravam a distância entre o direito e o cidadão. O positivismo jurídico, em face de uma nova realidade social, onde os aspectos do cotidiano, dos novos costumes e da presença maciça das camadas menos favorecidas, criam uma atuação de inflexibilidade diante de situações jurídicas, como se o Direito não fizesse parte do mundo das Ciências Sociais, e vivesse em um mundo em que a observância dos aspectos gerais, ${ }^{8}$ "não devam constituir" elementos da análise jurídica.

Essa situação viola direitos constitucionais gera a necessidade urgente de que repensemos nossas práticas profissionais na justiça, e que busquemos com nossas ações, constituir um Estado mais justo e consequentemente um

\footnotetext{
${ }^{8}$ Economia, desemprego, violência, exclusão, desigualdade, e tantos outros aspectos da vida cotidiana. 
Judiciário verdadeiramente democrático, onde o Estado de Direito seja alcançado por todo cidadão. "O agravamento da exclusão social no país e a fragilidade demonstrada pelo poder público na execução das atividades jurisdicionais, reforçam a convicção de que o setor precisa de modificações profundas" (VIEIRA, 1995, p. 10).

É importante, ainda, que repensemos a formação acadêmica dos profissionais que operam o direito ${ }^{9}$, pelo aprofundamento dos conhecimentos oriundos da Filosofia, da Sociologia, da Ciência Política e áreas afins, sem os quais, estes profissionais serão meros técnicos, preocupados apenas com a aplicação da lei, como realização do Direito, completamente alheios às múltiplas circunstâncias do fato jurídico, ampliando o abismo existente entre o Judiciário e a realidade social do Brasil.

Os métodos interpretativos clássicos, levam, assim, em nossos dias, a uma verdadeira crise do judiciário. Além de ser, pois, uma crise na substância ao bom exercício da prestação jurisdicional, é fundamentalmente uma crise de visão jurídica. (CIRILO, 2003, p.1).

As práticas autoritárias nos interrogatórios de réus pobres podem induzir as respostas dos acusados, além do tratamento degradante e desumano na realização dos inquéritos, onde muitas confissões são obtidas sob tortura, sem que nada seja feito pela autoridade judiciária para a apuração desses fatos (ANISTIA INTERNACIONAL, 2001, p.98).

Posturas de inércia diante de irregularidades denunciadas pelos presos, mostra a o total descrédito que do judiciário para com a pessoa do acusado, pois seu depoimento, traz a marca do crime cometido, e o entendimento do magistrado, acaba por compreender a denúncia do réu como uma estratégia de sensibilizá-lo na busca da absolvição (MAIA, 2002, p.42).

Tais atitudes do Judiciário, só reafirmam as posturas autoritárias direcionadas para certos segmentos da sociedade, o que demonstra a falta de visão humana do profissional da área jurídica, a precariedade de sua formação intelectual que o distancia do compromisso com a busca verdade, tornando-se um instrumento de dominação estatal, comprometendo a distribuição da Justiça.

Nossa estrutura jurídica é baseada numa realidade 'democrática' conservadora, que atua como instrumento de dominação de classe, mantendo o 'status quo', prevalecendo o direito convencional e vigente, do mais forte. No mais a forma de dominação racional é baseada numa lógica de uma tirania de dilúvio legislativo, em que o país está mergulhado, agravada

\footnotetext{
${ }^{9}$ Uma vez que consideramos grave a ausência de conteúdo sociológico e político na história acadêmica dos profissionais do Direito, limitados aos períodos iniciais dos cursos jurídicos, o que, ao nosso ver, agrava o tom de autoritarismo, comprometendo a formação humanista e a consolidação da democracia.
} 
pelo arbítrio dos dominadores mais astutos, que instituem mecanismos que lhes convêm, distribuindo louvores e censuras de acordo com a lógica de seus interesses.(...) Defendemos e buscamos uma nova concepção de justiça, dentro de uma perspectiva principiológica do ordenamento, bem como a busca da mediação e da conciliação na resolução dos litígios, como solução do justo. Neste sentido, é preciso modificar a formação do ensino jurídico a criar mecanismos processuais para manter com o outro um diálogo pleno, inteligível, num esforço entre as partes, visando a solução para fora da natureza rude e mágica, no reino do automatismo da lei, com a imposição autoritária da sentença. (CIRILO, 2003, p. 2).

A indiferença com a lesão sofrida por um "criminoso", é o retrato vivo da tolerância da sociedade moderna com ações brutais contra seres humanos fragilizados por sua condição social, pelo estigma de "bandido", onde a formação de sua culpa já se origina não do indício ou presunção de ter cometido um crime, mas de sua condição humana, de raça, classe e prestígio social.

Com a explosão da violência nos grandes centros urbanos, com as práticas desenvolvidas pelo crime organizado, terminamos por internalizar uma indiferença a tudo que possa parecer uma ameaça a nossas vidas, a nossa família e ao nosso patrimônio. Daí, a "saída de circulação" de certos "elementos" de nossa sociedade "civilizada", pode ser aceita com passividade e até causar uma sensação de alívio (ADORNO, CADIA, 1999, p. 67).

O autor Emilio Santoro faz reflexões significativas no texto "As Políticas Penais na Era da Globalização", nos traz uma reflexão de extrema relevância para a discussão:

A política de encarceramento e repressão penal não é mais utilizada para responder ao desenvolvimento da criminalidade, que permaneceu mais ou menos constante no período em que se afirmaram as novas políticas penais, mas para enfrentar a desestruturação social provocada pela retirada do Estado 'caridoso': estamos assistindo à passagem do Estado social ao Estado Penal. (SANTORO, 2002, p. 59).

É dentro dessa perspectiva de postura social que o Estado tem atuado em algumas circunstâncias, especialmente quando tem o poder de julgar e de punir, onde na busca da justiça há um encontro com a vingança.

\section{Conclusão}

Enquanto o Estado, através de suas instituições, não assegurar às populações que vivem em estado de miséria no Brasil, condições básicas para a realização e efetivação dos direitos humanos, haverá consequentemente a violação desses de direitos de forma direta ou indireta: passando pela fome, 
acesso limitado à educação, moradia, saúde, emprego até chegar a ausência de defesa e de igualdade de tratamento na esfera do Poder Judiciário.

Ao contrário do princípio constitucional de presunção de inocência, algumas classes sociais quando no banco dos réus, gozam do princípio da presunção de culpa, como se sua origem de nascimento, classe, poder econômico servissem como prova material contundente para sua condenação.

Não procuramos defender os que de algum modo infringiram 0 ordenamento penal, pois o jus puniendi é uma prerrogativa estatal que assegura a ordem social. Entretanto, deverá ser concretizado de forma igualitária para todos os componentes da sociedade, pobres ou ricos, pretos ou brancos intelectuais ou analfabetos. E para tal, é necessário que haja uma mudança de postura na interpretação e aplicação da Lei, na formação dos operadores do direito, para que a lei não tenha "dois pesos e duas medidas".

O crime está presente constantemente nas camadas populares ${ }^{10}$, daí um grande número de pessoas destas comunidades se encontrarem presas. Entretanto, tem sido comum vermos práticas delituosas realizadas por membros de classes abastadas, onde condenações isoladas se transformam em manchetes de jornais, diante da raridade da presença destas elites na vida cotidiana do cárcere no Brasil.

A elite criminosa dispõe de recursos suficientes para promover sua defesa quando necessário, e em muitas situações sequer chega a ser alvo de investigação. A condenação no Brasil por crimes "do colarinho branco", não é a regra, é a exceção, pois nossas penitenciárias parecem não ter lugar para quem tem "estirpe" e mata, ou rouba milhões.

A busca da verdade no processo penal Brasileiro ainda passa por um sombrio labirinto para os indefesos, já que nem todos os operadores do direito têm compromisso com a justiça social no Brasil, onde o tratamento jurídico penal dirigido às populações excluídas padecem de um tom autoritário e de uma legislação "mão-de-ferro"11.

É nessa perspectiva que o processo em sua prática se torna um instrumento de segregação subjetivo, menos visível e contundente de desrespeito aos direitos humanos, onde o aspecto dogmático e tecnicista na condução dos procedimentos se sobrepõe a formação humana e a garantia de um acesso digno e igualitário do cidadão ao Sistema de Justiça.

É como no dizer do mestre Paulo Freire em suas palavras quando observa que muitas vezes acreditamos erroneamente vivermos em uma sociedade de excelência:

10 Vimos todos os dias nos jornais, revistas, internet, programas de TV e censos penitenciários do mundo inteiro.

${ }^{11}$ Com o crescimento da criminalidade violenta (narcotráfico, crime organizado globalmente), crescem as posturas de endurecimento na aplicação da legislação criminal, sem a observância dos princípios protetores dos direitos fundamentais. 
Que excelência é essa, que dorme em paz com a presença de um sem-número de homens e mulheres cujo lar é a rua, e deles e delas ainda se diz que é a culpa de na rua estarem. Que excelência é essa que pouco ou quase nada luta contra as discriminações de sexo, de classe, de raça, como se negar o diferente, humilhá-lo, ofendê-lo, menosprezá-lo, explorá-lo, fosse um direito dos indivíduos ou das classes, das raças ou de um sexo em posição de poder sobre o outro. (FREIRE, 2002, p. 94-95).

A luta por um Judiciário democrático e cidadão, atento aos problemas sociais, e próximo das massas trabalhadoras e excluídas, dos desempregados, dos pobres e miseráveis, exige uma profunda mudança de conceitos, de posturas, de valores, onde a contribuição de cada profissional do direito engajado nas transformações sociais, numa ética profissional respaldada em princípios que valorizem a democracia, a justiça social e os direitos humanos, possa contribuir para que o acesso à Justiça no Brasil se torne o direito de todos, e não o privilégio de alguns.

\section{Referências}

ADORNO, Sérgio. Os Aprendizes do Poder. Editora Paz e Terra: RJ, 1997.

ADORNO, Sérgio. CARDIA, Nancy. Dilemas do Controle Democrático da Violência: Execuções Sumárias e Grupos de Extermínio. In. SANTOS, José Vicente Tavares dos (org). Violência em Tempo de Globalização. Hucitec: SP, 1999. P.74-75.

BARROS, Ana Maria de. Educação e Clientelismo: Os Educadores e a Educação Municipal no Nordeste. Idéia: João Pessoa, 2002.

BOBBIO, Noberto. O Futuro da Democracia: Uma Defesa das Regras do Jogo. Paz e Terra: RJ, 1986.

BRASIL. Constituição Federal de 1988. 31E, Saraiva: São Paulo.

BRASIL. Código de Processo Penal. 37E, São Paulo:1997.

BRASIL. Justiça e Cidadania no Brasil. Editora Korad Adanauer: SP, 2001.

BRASIL. Justiça com controle popular, disponível em:

http://www.dhnet.org.br/direitos/judiciario/papel_judiciario.htm. Acesso em 16/07/2003.

CAPEZ, Fernando. Curso de Processo Penal. Saraiva: SP, 2002.

CIRILO, José Airton. Crise na Visão Jurídica, e a busca de uma nova Justiça.

Disponível em: http://www.acmag.com.br/crise.html. Acessado em 16/07/2003;

FAORO, Raimundo. Os Donos do Poder. V.1. Editora Globo/USP: Porto Alegre/SP, 1975.

FREIRE, Paulo. Pedagogia da Esperança: Um Reencontro Com a Pedagogia do Oprimido. Paz e Terra: Rio de Janeiro, 2002.

HOLANDA, Sérgio B. Raízes do Brasil. Editora José Olímpio: RJ, 1988.

MAIA, Luciano Mariz. Tortura no Brasil: A Banalidade do Mal. In. Direitos Humanos: Os Desafios do Século XXI. Uma Abordagem Interdisciplinar, (org) Rubéns Pinto Lyra, Brasília, Jurídica, 2002. 
MIRABETE, Julio Fabbrini. Código de Processo Penal Interpretado. 8E, Atlas: São Paulo, 2000.

PINHEIRO, Paulo Sérgio. MENDEZ, Juan E. O'DONNELL, Guilhermo. Democracia, Violência e Injustiça, $O$ não-Estado de Direito na América Latina. Paz e Terra: São Paulo,2000.

PIOVESAN, Flávia. Direitos Humanos e o Direito Constitucional Internacional. Ed. Max Limonad: São Paulo, 1997.

SADEK, Maria Teresa. O Sistema de Justiça. Editora Konrad Adanauer: SP, 2001.

SANTORO, Emílio. Direitos Humanos os Desafios do Século XXI: uma abordagem interdisciplinar. Jurídica: Brasília, 2002.

SANTOS, Boaventura de Sousa. Pela Mão de Alice: O Social e o Político na Pós Modernidade. Cortez: São Paulo, 2001.

SCHEERER, Sebastian, apud, GOMES, Luiz Flávio. In. Revista Brasileira de Ciências Criminais. Editora Revista dos Tribunais: SP, №42, 2003.

SODRÉ, Nélson Werneck. Síntese de História da Cultura Brasileira. 12E. Difel: SP, 1984.

VIEIRA, José Ribas. Teoria do Estado: A Regulação Jurídica. Ed. Lumens Juris: Rio de Janeiro, 1995.

WEFFORT, Francisco C. Os Clássicos da Política Volume 1. 13 E, Ática: São Paulo, 2002. 